\title{
Reflections on Palaeolithic Cave Art, Girls at Puberty and the Origin of Religion
}

\begin{abstract}
It is not a stretch of imagination to link seclusion of girls at puberty with the Palaeolithic cave art. The widely accepted view about cave art suggests that the cave artists had been shamans. This shamanic origin can imply that the religion emerged in the times when the cave artists were active. It has already been posited in the relevant literature that the Venus figurines representing mobile art of the period suggests their connection to the rites of girls at puberty. This paper explores the possibility that there could have been a link between the cave artists and the girls at puberty. This connection means that the religion might have started with an association to the girls' puberty rites.
\end{abstract}

\section{Introduction}

Seclusion of girls at puberty had been discussed by several authours including Frazer (1993)1, Benedict $(1934)^{2}$, Richards $(1962)^{3}$ and Lincoln (1981) ${ }^{4}$. However, apart from Frazer, the other authours mainly looked at anthropological importance of this rite of passage. Arachige (2009) ${ }^{5}$ discussed the possible significance of these rites to the origin of religions. Even though on its face value this may seem as a long shot, in a previous article Arachige $(2010)^{6}$ suggested that there could well be a link between the seclusion of girls at puberty and the Palaeolithic Venus figurines. Arachige $(2009,2012)^{7}$ also argued that the seclusion of girls could have been practised at least 40,000 years as the spread of the motifs of seclusion on a geospatial basis indicates. This opens up the possibility of a substantial continuity of the said puberty rites since the Palaeolithic times ${ }^{8}$. If such continuity can be established, then, finding the roots of religion, as our today's perspectives on religion allow us to believe, in the seclusion does not seem far-fetched. Arachige $(2011)^{9}$ also hypothesised that the seclusion rites related to the Venus figurines might have branched off to other cultural traits in prehistoric Europe. In the present article, it is intended to bring together some of these ideas to form a foundation for a more cohesive hypothesis about the origin of religion.

\section{Road to Religion via Puberty Rites}

There is the widely accepted view of the existence of prehistoric shamanism as evidenced by Palaeolithic cave art. All prominent authors in this school, Lewis-Williams, Whitley $(2009)^{10}$, Clottes $(2011)^{11}$ have discussed this point of view in detail. If it can be shown that there is a connection

\footnotetext{
${ }^{1}$ Frazer, J 1993 (1922) The golden bough: $A$ study in magic and religion, Wordsworth Reference, Ware

2 Benedict, R 2005 (1934) The patterns of culture, Mariner Books, New York

${ }^{3}$ Richards, A. I 1982 Chisungu: A Girl's Initiation Ceremony among the Bemba of Zambia, Routledge, London

${ }^{4}$ Lincoln, B 1981 Emerging From The Chrysalis, Studies in Rituals of Women's Initiation, Harvard University Press

${ }^{5}$ Arachige, D 2009 The lure of noma: on the elegance of religion, Ocean Publishing, Perth

${ }^{6}$ Arachige, D 2010 Prehistoric Venuses and Puberty Rite, http://www.thelureofnoma.com

${ }^{7}$ See 5 above and Arachige, D 2012 Antiquity of Secluding Girls at Puberty. Available at SSRN: http://ssrn.com/abstract=2173172 or http://dx.doi.org/10.2139/ssrn.2173172

8 p. 10-21. Froese, T. 2013 Altered States and the Prehistoric Ritualisation of the Modern Human Mind. In: C. Adams, A. Waldstein, B. Sessa, D. Luke \& D. King (eds.), Breaking Convention: Essays on Psychedelic Consciousness, London, UK: Strange Attractor Press

${ }_{9}^{9}$ Arachige, D 2011 Witches, Shamans and the Girls at Puberty. Available at: http://www.thelureofnoma.com

${ }^{10}$ Chapter 7. Whitley, David. S. 2009. Cave paintings and the human spirit, Prometheus Books, New York (Kindle Edition)

${ }^{11}$ p24-25. Clottes, J 2011 Cave Art, Phaidon, Reprint
} 
between the prehistoric art, shamanism and the puberty rites, then, it is not difficult to take the next step of identifying the nexus between religion and girls' puberty rites.

When it comes to religion, a mechanistic framework with parallels to what is expounded by behaviourist school in psychology is so widespread among anthropological community as evidenced by the following comments of Atran ${ }^{12}$ about the supernatural agency. "In all cultures, supernatural agents are readily conjured up". The reason for this is that "natural selection has trip-wired cognitive schema" to detect external agents. This is more so because of the uncertainty associated with detecting danger. This impact of uncertainty results in a "hair-triggering of an agency-detection mechanism" lending "itself to supernatural interpretation." However, the existence of the supernatural is a universal cultural norm and its association to religion is widely accepted.

There are many different views about the origin of religion. Again, according to Atran (2002) ${ }^{13}$ religion can be defined as a community's costly and hard-to-fake commitment to a counterfactual and counterintuitive world of supernatural agents who master people's existential anxieties, such as death and deception ${ }^{14}$. The crux of the above definition is the involvement of supernatural agency in religion. The idea of such an agency is minimally counter-intuitive and thus, could take root in our psyche. As the puberty rites and idea of the perceived supernatural abilities of the girls at puberty is so entwined in the minds of many societies that it would seem very worldly, the connection between religion and seclusion of the girls at puberty becomes an overarching possibility. It can be posited that the supernatural agency was not necessarily something conjured up by our cognitive system developed through natural selection. The origin of the religion can be more mundane. No one would call Darwinism or the Theory of Relativity was a product of natural selection. Despite the fact that we can laboriously find an argument to prove the hand of natural selection, two key individuals conceived these ideas through their gift for synthesis. Similarly, some gifted individuals had some abilities, which others perceived as extraordinary. A series of behaviours, which resulted from such beliefs, gave rise to the belief in the supernatural among our prehistoric ancestors.

Furthermore, the present author believes that the above cognitive explanation is an attempt to see the religion in a Darwinian perspective in the hope that being able to conceptualize such an agencydetection mechanism and its probable connection to the existence of the supernatural alone can justify such a theory. But let us question how we know that such a universal mechanism can lead people to follow a focal person as we usually encounter in many religions and cults. In other words, how can we explain the specificity through universality, i.e. many followers one founder? In any shamanic culture, all members thus trip-wired by the natural selection would not end up as shamans. Given the status accorded to girls at puberty in early history where written records exist ${ }^{15}$, it is very probable that in the prehistoric times too, girls at puberty had also been considered to be

\footnotetext{
12 p71. Atran, S 2002 In Gods we trust: The evolutionary landscape of religion, Oxford University Press, New York 13 p4. ibid.

${ }^{14}$ The existence of the "supernatural agent" is even more prevalent in modern science. For an example, Charles Darwin is treated as the great genius, who discovered evolution "for the first time". For many great biologists, he is almost the supernatural genius who deposed God. This exemplifies how human behaviour accords people who stand above others in the eyes of the majority a 'supernatural' status and gathers followers. Thus, a following doesn't ensue from an ordinary person. A focal person, a Transcendental Social like an Elder from a tribe, a celebrity can only gather people around them. Any person deemed not to be special cannot be different to the rest in the eyes of the ordinary people and thus, is not worthy of a following. The present author discussed some of these ideas in the chapter 3 of "The Lure of NOMA", (Arachige 2009) ${ }^{15}$ Pliny. The Natural History. Quoted on p606. Frazer, J 1993 (1922) The golden bough: A study in magic and religion, Wordsworth Reference, Ware
} 
"special people". It is interesting to note the mention Whitely makes about the girls' puberty rites in the community of Luseno Indians in southern California. The young girls at the conclusion of their puberty rites painted their spirit helpers and left hand prints usually in red ${ }^{16}$. As Boas tells us in his book, "The Mind of Primitive Man", cultural traits such as the above, which "occur sporadically in regions far apart", should be carefully interpreted to deduce their continuity without change in various cultures from the prehistoric times ${ }^{17}$.

The puberty rites in various parts of the world continued to involve the seclusion and the belief of special powers of the girls at puberty. Sir James Frazer treated this liminal state, which placed such girls between heaven (not to see the sun) and earth (not to touch the ground). However, many researchers for various reasons would like to avoid discussing the supernatural aspect of these rites of passage. This attitude reminds of the behaviourist school of psychology, which ignored all subjective concepts not directly observable ${ }^{18}$. However, there had always been a deep involvement of supernatural factors in the life of a girl at puberty, which had been discussed in detail in another article $^{19}$. Even though all girls at puberty can have the potential to become shamans, the current proposition about the girls at puberty being associated with the origin of religion doesn't require them all to be 'special persons'. Some of them can always be special due to their special qualities; the rest, perhaps, their retinue. This can be further discussed in the background of possible connection between the founders of religion and their abnormal psychological conditions ${ }^{20}$. Many founders of religions were considered by their contemporaries to have special powers.

One major reason for the attitude of separating the supernatural aspect from the girls' puberty rites is the presence of puberty rites for boys, which are mainly rites of passage. For girls, there is more to puberty rites than mere celebration of a rite of passage. The perception that considering supernatural explanations is not scientific can be a very daunting factor for the scholastic community. Growing up in a place and time which now seem like a time capsule of cultural traits made the current authour realise how important the supernatural aspect was for the seclusion of pubescent girls (see also De Silva, 1981) ${ }^{21}$. Young girls were instructed not to eat certain oily food and not to wonder about alone in fear of being possessed (Arachige, 2011). When they walk about alone, they were asked to take a piece of iron or something made out of iron (De Silva, 1981; Narayan et al, 2001) ${ }^{22}$. The girls were feared because of 'bad energy', carried by them. Unless we are not ready to think like the people whom we are studying or consider the most significant aspects, if not one of the most significant aspects, of their cultural practices, we are throwing out key phenomenological content of our investigations. This may mean being blind to the facts in order to be scientifically acceptable. In the ensuing discussion, I would like to mainly focus on the 'magical' world where people whose minds were not affected by the idea of modern day scientific rationalism.

\footnotetext{
${ }^{16}$ Chapter 4. Whitley, D. S 2009 Cave paintings and the human spirit, Prometheus Books, New York (Kindle Edition)

${ }^{17}$ Chapter 9. "Early Cultural Traits" in Franz, B 1938. The Mind of Primitive Man, The Macmillan Company, New York

18 p63. Fromm, E 1973 The Anatomy of Human Destructiveness, Pimlico, London

${ }^{19}$ Arachige, D 2010 Prehistoric Venuses and Puberty Rite, http://www.thelureofnoma.com

${ }^{20}$ Chapter 3. Arachige, D 2009 The lure of noma: on the elegance of religion, Ocean Publishing, Perth

${ }^{21}$ p35-36. De Silva, D W 1981 Puberty rites for the Sinhalese female. Lambda Alpha Journal of Man, 13. Available at: http://soar.wichita.edu/dspace/bitstream/10057/1764/1/LAJ+V+13_p35-46.pdf

22 p225-238. Narayan, K.A, D.K. Srinivasa, P.J. Pelto and S. Veerammal 2001 Puberty rituals, reproductive knowledge and health of adolescent schoolgirls in South India, Asia-Pacific Population Journal 16(2).
} 


\section{Palaeolithic Shamans, Religion and Cave Art}

According to the most widely accepted view of the Palaeolithic art, early shamanic practice can arguably be related to the origin of the earliest-known cave drawings. According to Lewis-Williams $(1997)^{23}$, both representational and geometric image making in the Palaeolithic period was done by early shamans in an altered state of consciousness induced, perhaps, by psychedelic plant material. Oxford Dictionary defines shaman as "a person regarded as having access to, and influence in, the world of good and evil spirits." After accepting that the Palaeolithic cave artists were prehistoric shamans, Whitley (2009) argues the case for the association between religion and cave art. He proposes that the shamanic ecstasy as promoted by Mircea Eliade is a myth and the shamans are generally suffering from affective disorders ranging from minor depression to schizoaffective disorders. He believes that given the human nature conditioned by our evolutionary history and cognitive development, as discussed in preceding paragraphs, religion arose from already present cognitive roots through organization of beliefs in prehistoric western Europe. Note the importance of a natural cause to this prehistoric form of shamanism.

In the light of recorded connection between perceived supernatural abilities such as negative impact of the evil eye or touch and the girls at puberty it can be deduced that in the periods prior to the written history girls at puberty were deemed to have suffered from some psychological conditions, which were perceived by others as either as detrimental or beneficial to the community depending on the circumstances and perspectives. These traditions persisted to the historical times after losing its original context. It seems that valuable contributions by them as people with psychic abilities were possibly undermined by the later traditions.

It is interesting to note that in case of unipolar depressive disorder, one of the mood disorders Whitely mentions, there is a well-established gender difference ${ }^{24}$ observed in many countries around the world ${ }^{25}$. A WHO Report also mentions that ${ }^{26}$

"Despite later onset, some studies report that women experience a higher frequency of hallucinations or more positive psychotic symptoms than men (Lindamer et al. 1999) ${ }^{27}$. Similarly, while the population prevalence rates of bipolar disorder appear not to differ, gender differences occur in the course of the illness. Women are more likely to develop the rapid cycling form of the illness, exhibit more comorbidity (Leibenluft, 1997) ${ }^{28}$ and have a greater likelihood of being hospitalized during the manic phase of the disorder (Hendrick, Altschuler, Gitlin et al. 2000) ${ }^{29}$."

\footnotetext{
${ }^{23}$ p321-342. Lewis-Williams, J. D 1997 Harnessing the Brain: Vision and Shamanism in Upper Palaeolithic Western Europe, in Beyond Art: Pleistocene Image and Symbol, Proceedings of a Paul L. and Phyllis Wattis Foundation Endowment Symposium, ed. by Margaret W. Conkey, Olga Soffer, Deborah Stratmann \& Nina C Jablonski, Wattis Symposium Series in Anthropology, Memoirs of the California Academy of Sciences, No. 23, University of California Press, California

${ }^{24}$ World Health Organization, Gender disparities and mental health, Retrieved on 9 July 2015. Available at: http://www.who.int/mental_health/prevention/genderwomen/en/

25 p248-249. Carson R. C, Butcher, J. N, Mineka, S and Hooley, J.M 2007 Abnormal Psychology, 13th Edition, Pearson, New Delhi

${ }^{26}$ Psychologist Julian Jaynes believe that it is easier for women to become oracles, as their brains are less localized than those of men. p344. Jaynes, J 1990 The Origin of Consciousness in the breakdown of the bicameral mind, Penguin, London

${ }^{27}$ p61-67. Lindamer, L.A et al 1999 Gender-related clinical differences in older patients with schizophrenia. Journal of Clinical Psychiatry, 60

${ }^{28}$ p163-173. Leibenluft, E 1997 Women with bipolar illness: clinical and research issues. American Journal of Psychiatry, (153)

29 p393-396. Hendrick V, Altshuler L.L, and M.J. Gitlin et a/2000 Gender and bipolar illness. Journal of Clinical Psychiatry, (61)
} 
Major mood disorders show some major gender differences and the females are susceptible to it at roughly twice the rate of the males ${ }^{30}$. Thus, if the affective disorders helped the emergence of shamans in the Palaeolithic times, the most of them had to be females. As mental diseases cannot be totally stripped off the cultural context, it is not sure how gender bias played its role in those prehistoric times. In historic times, it was the female of the species who communicated with the supernatura ${ }^{31}$ or had physical contact ${ }^{32}$ with it. As Scientific American puts it, "Extraordinarily for misogynist Greece, the Pythia was a woman and ......the Pythia did not inherit her office through noble family connections." ${ }^{33}$. Even if an ordinary person smelled the pneuma, the gas arising from a cavern deep down in the earth, which sent the Pythia to her trance, that person didn't go into the oracular trance. So the Phythia was special. In prehistoric times, this could have been even more prominent and the dark, deep Palaeolithic caves might have served the prehistoric Phythias well ${ }^{34}$. This same misogynist attitude might have left the girls at puberty with only the evil influences. Given the prevalence of female figurine in the Palaeolithic times, it is probable that the women were stripped off their due recognition after an early acceptance.

\section{Shamanic Powers in Women}

In the Palaeolithic times, it is believed that the hunter-gatherers roamed the Earth. From observing the hunter gatherer communities which persisted to more recent times, Anthropologists believe that due to the commitment to care and carry the young and the time taken to become a skilful hunter, for women, hunting which provides a high quality diet is not profitable ${ }^{35}$. Usually, women, children and grand children in foraging societies collect plants, shellfish and insects ${ }^{36}$. Thus, women should have had more knowledge about the vegetation that could be consumed and their specific qualities. If this argument extended, it can be easily seen that they had the best opportunity to see which plants were psychedelic and which were edible herbs. Thus, the first shamans, even if they were dependent on such psychedelic plant material, were more likely to be females of the clan. However, women might have had a natural inclination to portray extraordinary behaviours in the minds of the ancients through the perceptions about their puberty. The special treatment attributed to prehistoric women can be further corroborated by the skeletal remains of a woman considered to be a shaman and discovered at Dolni' Vestonice in eastern Europe ${ }^{37}$.

As was discussed by many authours, the place of the female as a person who is supernaturally gifted has been recorded in so many ways. Even though the period referred to by these authours is more recent, the attitudes might have persisted from the Palaeolithic times. One recorded example comes from the studies on trepanning undertaken by the famous Paul Broca and his contemporaries. It is

\footnotetext{
${ }^{30}$ p675-689. Pitychoutis P.M, Papadopoulou-Daifoti, Z 2010 Of depression and immunity: does sex matter? The International Journal of Neuropsychopharmacology, 13

${ }^{31}$ See the historical reports on Pythia, Cybills etc.

${ }^{32}$ Herodotus, Book 1.181-182

${ }^{33}$ Hale J. R., de Boer J. Z, Chanton J. P and H. A. Spiller 2003 Questioning the Delphic Oralce, Scientific American

${ }^{34}$ Many authours including Lewis-Williams and Wheatley finds the air quality within the Palaeolithic caves to be poor.

35 p156-185. Kaplan H, Hill K, Lancaster J, Hurtado, A. M, 2000 A theory of human life history evolution: Diet, intelligence, and longevity, Evolutionary Anthropology, 9:4

${ }^{36} \mathrm{http}: / /$ www.britannica.com/topic/hunting-and-gathering-culture. However, according to some authours, this formulation also based on observing the present day societies, suffers from lack of direct evidence as much as the other view of larger participation of the female in hunting. See p.82 of Adovasio J.M, Soffer, O and Page J 2007. The Invisible Sex, Smithsonian Books, Ney York

${ }^{37}$ Tedlock, B 2005 The woman in the shaman's body: Reclaiming the Feminine in Religion and Medicine, Batman, NY (Kindle Edition)
} 
an uncanny tribute to Broca's brilliance to get an area of the human brain named after him. After studying the skulls from Neolithic Period it was Broca who proposed that the trepanning was performed to cure illnesses such as epileptic seizures. Trepanning, according to him, was done when the patient was young. If the patient withstood the ordeal and survived, then, at death, amulets were made out of such trepanned skulls and were used as a prophylactic against all other diseases ${ }^{38}$. Almost half of the skulls found were females. Contrast the practice of such after-death veneration of the body parts or other aspects of the dead personalities with our belief in the influences of many founders of religion, the Son of God, gods and goddesses or Saints who are not physically present among us. After ignoring the specialities, at least in the spirit of the action, all these have underlying interactions. It also is interesting to note that a special case called $T$ Sincipital was almost exclusive to female skulls ${ }^{39}$. The view is that this procedure was a result of a religious ritual performed over many years.

Given the major emphasis of the puberty rites are on the rather sinister aspect of the supposed supernatural powers of the girls, it is difficult to see how this could have led to admiration which is common in a religious inspiration. The answer can be twofold. The girls were mainly adored for their ability to punish the enemies, who had to be many given the competition for the limited resources. Punishing enemies is a tradition, which continued to Roman Period in Europe ${ }^{40}$. As an example, written evidence was discovered at the temple of Goddess Minerva at Roman Baths in Bath, England, asking her help to curse their enemies ${ }^{41}$. Similarly, it was the statue of a goddess Artemis at Pallenne the gaze of which could be detrimental ${ }^{42}$. Also note that Lincoln $^{43}$ considers the Persephone myth is also associated with the puberty rite of seclusion. Persephone and Demeter are the mythic characters associated with the Eleusinian Mysteries in Ancient Greece. This connection between the goddesses and the puberty rites arguably going back to Minoan Civilization of ca. 2000 $\mathrm{BC}^{44}$, also accentuates the religious tendencies associated with the girls' puberty. The other possibility is a later revisionist attitude to only focus on the harmful side of their perceived abilities. This can very well be the case as the girls at puberty in Umnak Island were considered as having healing powers and her saliva was used to treat rheumatism ${ }^{45}$. Apache Indians also considered the girls at puberty as a source of supernatural blessing ${ }^{46}$. It is human to shift the focus depending on the prevalent cultural whims. The discovery of psychedelic plants can be such a turning point, which later helped more men to acquire supernatural or shamanic powers. Over time, the power struggle between male and female shamans could have turned the scales in favour of the male shaman. Female shaman who lost her prominent place could not be totally replaced due to her natural gift of "supernatural powers" and continued in the roles like that of the Phythia.

\footnotetext{
${ }^{38}$ p223-228. Munro, R. 1897 Prehistoric Problems, William Blackwood and Sons, available at http://books.google.com/ 39 p236-238. See above publication.

${ }^{40}$ Even in recent past, in Sri Lanka, there were people who were highly admired for their ability to write poetic curses, cast black magical spell on someone's enemies. These same people could do the exact opposite when asked by a client.

${ }^{41}$ See http://www.romanbaths.co.uk/walkthroughs/roman-worship (Retrieved on 27 July 2015)

42 p131. Ginzburg, C 1992 Ecstasies: Deciphering the witches' Sabbath, Penguin Books, London

43 p71-90. Lincoln, B 1981 Emerging From The Chrysalis, Studies in Rituals of Women's Initiation, Harvard University Press 44 p75. ibid.

45 "During this time the girl is believed to have healing powers. An old man with rheumatism was brought to the author's informant during her confinement so that she could rub his aching knees with her saliva, which is said to have stopped the pain."-p145-148. Shade, C. I 1953 The Girls' Puberty Ceremony of Umnak, Aleutian Islands, American Anthropologist, 53(1). Available at http://onlinelibrary.wiley.com/doi/10.1525/aa.1951.53.1.02a00380/pdf

${ }^{46}$ p22. Benedict, R 2002 The Diversity of Cultures, Cultural Sociologyed. by Lyn Spillman. Blackwell Publishers Ltd.
} 


\section{Role Played By the Caves in Puberty Rites}

The research done by Sharpe and colleagues, point out that in Rouffignac Cave, out of seven fluters five were women and girls some of whom were only about five years old ${ }^{47}$. These authours also point out that the shamanic hypothesis of Lewis-Williams brakes down as the fluters had to have poked the fingers in instead of fluting the surface, had they tried to get closer to the sacred world lying behind the walls. Furthermore, some fluters were children, who were unlikely to have performed as shamans ${ }^{48,49}$. Similarly, the analysis of the measurements done on the hand stencils found in El Castilo in Spain and France and Gargas and Pech Merle Caves in France showed a majority to be female hand stencils (about 75\%) ${ }^{50,51}$. This doesn't prove us that these females were kept in the caves or we can have complete faith on the soundness of the analytical basis of such investigations. But it is not simply a heightened state of imagination. (Clottes, 2011) after many years of researching the caves writes that given the abundance of female motifs in caves, the prehistoric people might have thought the caves to be female ${ }^{52}$. Add this to the female behinds and pubic regions depicted in these caves. Presence of many female contours without heads and feet can be perceived as girls or women sleeping on the side ${ }^{53}$. Gimbutas discussed the "reclining women" found sculpted in relief in the cave of La Madeleine with one arm and both legs upraised ${ }^{54}$. Gimbutas assumed these women were in labour. But, if they were in labour, wouldn't they be known as "women in labour" rather than "reclining women"? Isn't the first impression rather than a laboured interpretation more close to the truth? On the other hand, what facts do we have to confirm the birthing practices in prehistoric times were similar to ours? It is well known that both reclining and squatting birthing positions are practised even in modern times. Thus, these women we meet in the La Madeleine Cave can well be reclining and someone else depicted them on the walls. It can well be other women with more skilful hands and imagination who depicted their fellow inmates in such a manner. Also note that another reclining woman opposite a sorcerer was depicted in Gabillou Cave in Dordogne, France. This woman, also without a head was described by Clottes ${ }^{55}$. He also described another reclining female figure in low relief on rock of La Magdelaine des Albis Cave in Tarn, France ${ }^{56}$. Clottes (2011) mention that the female genitals or typically the pubic triangles ${ }^{57}$ were represented in European cave art from the Aurignacian on, as the caves were

\footnotetext{
47 p937-947. Sharpe, K \& Van Gelder, L 2008 Women and girls as Upper Paleolithic Cave 'Artists': Deciphering the sexes of finger fluters in Rouffignac Cave. Available at http://www.ksharpe.com/word/AR107.htm; Sharpe, K \& Van Gelder, L. 2006 Evidence for Cave Marking by Paleolithic Children. Antiquity 80:310.

${ }^{48}$ Sharpe, K \& Van Gelder, L. 2006 a Human Uniqueness and Upper Paleolithic 'Art': An Arachaelogist's reaction to Wentzel Van Huyssteen's Gifford Lectures. Available at http://www.ksharpe.com/Word/AR97.htm

${ }^{49}$ Cambridge Archaeologist Jess Clooney proposed through her research the most prolific fluters in in Rouffignac Cave was a three-year-old female child. http://www.bbc.co.uk/news/entertainment-arts-15109188 retrieved on 27 July 2015

${ }^{50}$ The article published in National Geographic News on 16 June 2009. "Prehistoric European Cave Artists Were Female", at news.nationalgeographic.com/news/2009/06/photogalleries/cave-handprints-actually-women-missions-pictures/

${ }^{51}$ p746-761. Snow, D 2013 Sexual Dimorphism in European Upper Paleolithic Cave Art, American Antiquity, Number 4 / October 2013, (16). Available at http://dx.doi.org/10.7183/0002-7316.78.4.746

52 p147. Clottes, J 2011 Cave Art, Phaidon, Reprint

53 p214-215. Also see p218. Note that there is more than one such silhouette in the same place. Clottes, J 2011 Cave Art, Phaidon, Reprint

54 p105. Gimbutas, M. 1991 The Language of The Godess, HarperSanFrancisco

${ }^{55}$ p124. Clottes, J 2011. Cave Art, Phaidon, Reprint

56 p262. ibid

${ }^{57}$ The pubic triangle is the popular belief about these motifs. Arachige questioning this interpretation in one blog post asks whether these triangles can be thought of as motifs representing chastity or promises of chastity or a chastity belt (see $\mathrm{http}: / /$ thelureofnoma.com/posts-are-here/page/2/). Or it may also be a motif for menstrual women or the pubertal girls.
} 
perhaps thought as female ${ }^{58}$. It may well be the case these were drawn by women to mark their territory or just to get rid of boredom. The point is that some libidinous male occupants of the cave did not necessarily do these markings. It is a possibility that these artists lived in those caves for some span of time ${ }^{59}$ when we are look at "seclusion huts" with many women ${ }^{60}$.

And consider the time taken to get the eyes accustomed to the environment inside a dark cave ${ }^{61}$. If the person lives in the cave for some time, it would be easy for the person to get used to the darkness and do many things by the flicker of a lamp. If the oil lamps were burning all the time the drawings were done, there could have been more carbon dioxide inside the cave making long stays very uncomfortable. On the other hand, burning fat had to blacken the cave roof badly. Similar arguments might help us to believe that the persons who drew on the Palaeolithic cave walls stayed in these caves long enough to get their eyes accustomed to the darkness.

There can also be a supernatural aspect to this. The women hidden in those deep dark caves might have been expected to see without seeing and walk without walking. In these early days, they were expected to see whether the herds of bison or mammoths would come to their vicinity soon; walk to the places where their enemy tribes lived; see the future for the Elders or travel to places where the dead souls of the ancestors roamed ${ }^{62}$. The human nature across the globe when all the trappings, which the culture and socio-economic landscape imposed on it, are peeled off is similar. Diamond ${ }^{63}$ vividly explained this about intelligence and civilization. In the prehistoric times all human beings might have thought about various aspects of their lives in a similar light. Frazer ${ }^{64}$, Lang ${ }^{65}$ and Bastian ${ }^{66}$ collected a large number of examples about rituals of primitive people to prove this same fundamental similarity arising from independent development through the psychic unity of mankind. Thus, when removed from the cultural aspects, the rituals and beliefs surrounding the girls' puberty can show us that the maidens were thought to have special powers to see without seeing and travel without travelling. In the minds of the ancients, there was no place for mental illnesses as they might have thought about these as the afflictions caused by a dead relative or a communication with gods or goddesses. Jaynes ${ }^{67}$ describes many examples on how all humans before the breakdown of

\footnotetext{
58 p147 and p255. ibid

59 The paper mentioned below hints at an interesting possibility that Bolombas cave being a place associated with the girls' seclusion as the presence of red ochre suggests, despite being a weak argument to connect the two. p.10-21. Froese, T. 2013 Altered States and the Prehistoric Ritualisation of the Modern Human Mind. In: C. Adams, A. Waldstein, B. Sessa, D. Luke \& D. King (eds.), Breaking Convention: Essays on Psychedelic Consciousness, London, UK: Strange Attractor Press.

${ }^{60}$ DuPlooy, S 2006 Female initiation: becoming a woman among the Basotho, M.Sc.Sc Thesis, Department of Anthropology, the University of the Free State, South Africa (available at http://etd.uovs.ac.za/ETD-db//theses/available/etd-08102007142005/unrestricted/DuPlooyS.pdf)

${ }^{61}$ Note that the 19th century scholars didn't want to believe that prehistoric people due to the darkness inside these caves did the cave art. Only after the discovery of sandstone lamps inside the caves, they decided to accept the view.

${ }^{62}$ In the place, the present author grew up young maidens who were not bitten by a dog were sought after by the shamans.

Such women were supposed to have some shamanic powers. At night after a series of ritualistic chants, these maidens were supposed to divine with a blackened surface of a saucer on which a flicker of an oil lamp danced. Not every such maiden could perform the task. Some women were supposed to have an innate ability. They were supposed to seek help from Hanuman, the Hindu Monkey God, or Anjanam Devi (Goddess of Anjanam) in their psychic travels. Hanuman or Anjanam Devi was supposed to take the seeker to places so that she could perform her tasks.

63 p15-32. Diamond, J 2005 Guns, Germs and Steel, Vintage, London

${ }^{64}$ Frazer, J 1993 (1922) The golden bough: A study in magic and religion, Ware: Wordsworth Reference

${ }^{65}$ Lang, A 1900 The Making of Religion, 2nd Edition, Project Gutenburg

${ }^{66}$ p30-38. Lowie, R 1937 The History of Ethnological Theory, Farrar \& Rinehart Inc, New York

67 Jaynes, J 1990 The Origin of Consciousness in the breakdown of the bicameral mind, Penguin, London
} 
bicameral mind ${ }^{68}$ thought about them as conversing with the gods. A lone mental patient had been easily drowned in such a population-wide phenomenon. The important point is that for our prehistoric ancestors, the voices heard and visions seen through a mental illness could have been mere expression of external agency, not perceived to be ailments. Thus, any mental illness suffered by some adolescent girls due to various socio-cultural factors ${ }^{69}$ was very likely to be attributed to the external factors, which we call supernatural. This can be well within the sphere of shamanism. In another article, the special place of women in shamanic practices was discussed by the present authour ${ }^{70}$. Thus, it is very probable that the cave dwelling women were supposed to perform a special task for the clan.

\section{Concluding Remarks}

One major point, current author considers with some reservations is the reality of "Creative Explosion" which took place in the Palaeolithic times about 40,000 years ago. How could we be so certain that long before the humans drew on cave walls they didn't draw on sand, bark or rock which disappeared in the passage of time? How could we be so certain that for ages they had a taboo imposed on them not to represent the nature in any other form? How could we be sure some new socio-cultural change didn't lead them to see the animate and inanimate world around them in a different light? As the archaeological findings show, our ancestors had used shells, indicating their ability to grasp symbolism, at least 50,000 years earlier than previously thought ${ }^{71}$. Could the cave art, thus, be the product of a cultural revolution rather than a creative explosion?

Whatever the reasons for the emergence of both mobile and parietal art in the Palaeolithic Europe were, it is very probable what we see today could be due to a system of thinking involving the supernatural abilities of the players in this drama. Scholars proposing the shamanic practices as the cause of cave art as well as the ones suggesting the involvement of mental disorders are trying to uncover an abnormality such as hallucinations to trigger the action. Some even proposed the mind of these ancient artists showed some limitations, which were evident in autistic people before they acquire language skills ${ }^{72}$. In summary, the current prevalent thinking places the importance on some form of abnormality of the prehistoric person. The proposition explained in the present article is not contradicted by the role played by perceived abnormalities of the girls at puberty. These perceived abnormalities were bordering on the supernatural abilities attributable to external agency in modern parlance. Think of the belief that a simple look from a girl at puberty could make weather turn bad ${ }^{73}$. In the mind of the our prehistoric relatives, she could be treated among those with shamanic powers. It is interesting to note that the gender of shamans was not just male. There is evidence as given in the preceding sections that the majority or equal proportion of shamanic practitioners could

\footnotetext{
${ }^{68}$ Note that the bicameral mind hypothesis is not a widely accepted viewpoint. However, the examples on hallucinogenic nature of the mind are the key consideration for the current topic.

${ }^{69}$ We don't have any prehistoric evidence to this. But a crude deduction from the modern times makes the assumption of mental illness of the adolescents somewhat realistic.

${ }_{70}^{70}$ Arachige, D 2011 Witches, Shamans and the Girls at Puberty, http://www.thelureofnoma.com

71 p307-314. Bar-Yosef Mayer, Daniella E., Vandermeersch, Bernard \& Bar-Yosef, Ofer 2009 Shells and ochre in Middle Paleolithic Skhul and Qafzeh, Israel: indications for modern behavior. Journal of Human Evolution, (56)

See also Henshilwood, C.S., d'Errico, F., Vanhaeren, M., van Niekerk, K. and Jacobs, Z 2004 Middle stone age shell beads from South Africa, Science 304: 404 . Also note the modern discoveries about the use of symbolically meaningful objects by the Neanderthals.

72 p. 165-91. Humphrey, N 1998 Cave Art, Autism, and the Evolution of the Human Mind, Cambridge Archaeological Journal 8:2

${ }^{73}$ A Chinook Indian belief. p599 of Frazer 1993.
} 
have been females. There could have been a significant impact of girls at puberty on the population of shamans or the future shamans as the persistence of puberty rites very similar in symbolism prevailed over time and space. If the religion was shamanic in origin, the contribution of the girls at puberty should be very substantial as many artefacts representing the prehistoric Venuses can be thought of as associated with the pubertal rites of girls in their origin.

The author preserves the full copyright of this document.

How to reference the current document:

Arachige, D (2015) Reflections on Palaeolithic Cave Art, Girls at Puberty and the origin of Religion, www.thelureofnoma.com 